\title{
O PRINCÍPIO DA SOLIDARIEADE E OS IMPACTOS SOCIOAMBIENTAIS CAUSADOS PELA SOCIEDADE CONSUMOCENTRISTA
}

\author{
Lucas Dalmora Bonissoni* \\ Rogerio da Silva**
}

\section{RESUMO:}

O presente artigo visa analisar os aspectos da sociedade de consumo ao consumocentrismo, que tem como característica principal satisfazer vontades pessoais, e elevar a condição dos seres humanos a mercadorias vendáveis. Por conta disso, desponta a necessidade de observar o princípio da solidariedade como uma qualidade ética e um valor absoluto de cada pessoa, que tem como objetivo estar ao lado dos excluídos, para participar de suas lutas que os afastam do ciclo social, como forma de frear os impactos socioambientais que atingem não só o meio ambiente, mas a sociedade como um todo, causando reflexos de reconhecimento ao próximo.

Palavras-chave: Sociedade de Consumo; Sociedade Consumocentrista; Princípio da Solidariedade; Reconhecimento; Impactos Socioambientais.

\section{THE PRINCIPLE OF SOLIDARITY AND THE SOCIAL-IMPACT IMPACTS CAUSED BY CONSUMER-CENTER SOCIETY}

\begin{abstract}
:
This article aims to analyze the aspects of the consumer society, which have as their main personal consumption resources and raise the condition of human beings to goods sold. Therefore, give up the need to observe or the principle of solidarity, as an ethical quality and an absolute value for each person, who aims to be alongside the excluded, to participate in their struggles that are outside the social cycle, as a way to curb the social and environmental impacts that affect not only the environment, but society as a whole, cause recognition reflexes in the next.
\end{abstract}

Keywords: Consumer society; Consumocentrist Society; Solidarity Principle; Recognition; Socioenvironmental Impacts.

\section{INTRODUÇÃO}

\footnotetext{
* Mestrando em Direito na Universidade de Passo Fundo - UPF, bolsista do Programa de Pós Graduação em Direito, vinculado à linha de pesquisas Relações Sociais e Dimensões do poder. Endereço postal: Rua Herculano Hércules Zanuzzo, 632, Sala 02 - Industrial, 89770-000 - Seara, SC. e-mail: lucasdbonissoni@ icloud.com.

** Vice-Reitor da Universidade de Passo Fundo - UPF, especialista em Contratos e Responsabilidade Civil UPF, Mestre e Doutor em Direito pela Universidade de Santa Cruz do Sul - UNISC. Endereço postal:

Universidade de Passo Fundo, Faculdade de Direito. Campus I, BR 285, Km 171, Sao Jose, 99001970 - Passo Fundo, RS. e-mail: rogerio@upf.br
} 
O presente artigo inicia seu estudo, com base teórica em Bauman, apresentando as principais características da sociedade de consumo, que classifica a forma individualista do ser humano de agir e se comportar, pensando exclusivamente em atingir a satisfação de suas vontades pessoais, rejeitando todas as outras opções culturais alternativas. A outra característica apontada no artigo é a comodificação do consumidor, ou seja, eleva-o ao status de mercadoria vendável, vinculada a integridade física do sujeito, no sentido de que as pessoas acabam consumindo apenas para se autopromoverem e desenvolverem identidades por meio do consumo.

Porém, devido à evolução do consumo ocorrida na sociedade contemporânea, passase o estudo para a fase da sociedade consumocentrista. Nesse ápice, o cidadão torna-se refém do próprio consumo, onde o produto final acaba sendo o "fim em sua existência", isto é, seus desejos pelo mercado transformam-se no verdadeiro centro do universo. Diante dessa situação, a sociedade consumocentrista acaba perdendo os sentimentos de reconhecimento ao próximo, buscando a felicidade apenas no momento de adquirir novos pertences.

Para tanto, no segundo capítulo, busca-se com o princípio da solidariedade encontrar uma nova maneira de relacionar as pessoas, considerando que a solidariedade tem como conceito partilhar valores e obrigações sociais para cada cidadão, implicando responsabilidades morais de reciprocidade junto com o próximo, que acaba sendo excluído pela sociedade consumocentrista.

Contudo, no terceiro capítulo, demonstra que os impactos causados não se estendem apenas em problemas sociais, posto que a sociedade consumocentrista também atinge o meio ambiente, devido a produção em larga escala das grandes empresas, que além do lucro, produzem cada vez mais para atrair e fidelizar novos clientes. Nesse sentido, o artigo apresenta que a sociedade consumocentrista gera problemas considerados socioambientais, por abarcar danos diretamente ligados à sociedade e também ao meio ambiente.

Dessa forma, o objetivo central deste artigo é descrever os impactos socioambientais originados pela sociedade consumocentrista e apontar como possível meio de solução a observância do princípio da solidariedade como retomada do reconhecimento ao próximo, com o intuito de aflorar a consciência racional dos interesses em comum.

Os procedimentos metodológicos adotados para a realização dessa pesquisa consistiram no método dedutivo, sendo a pesquisa de caráter qualitativo, tendo sido adotada a técnica de pesquisa bibliográfica para sua elaboração. 


\section{A EVOLUÇÃo do CONSUMO: DA SOCIEDADE DE CONSUMO AO CONSUMOCENTRISMO}

As relações de consumo existem desde os tempos mais primórdios, sendo inclusive uma prática de sobrevivência humana, posto que representam situações básicas de cada indivíduo para satisfação de suas necessidades pessoais. O consumo em si próprio torna todos os sujeitos consumidores, porque é uma atividade que é praticada a todo instante, seja para alimentação, vestuário, e qualquer outra atividade que seja indispensável para o dia-a-dia do ser humano, "o consumo é algo banal, até mesmo trivial. É uma atividade que fazemos todos os dias, por vezes de maneira festiva, ao organizar um encontro com os amigos, comemorar um evento importante ou para nos recompensar por uma realização particularmente importante" (BAUMAN, 2008, p. 37).

Com o passar dos anos novas transformações ocorreram no globo, principalmente por conta do advento da globalização trouxeram significativas contribuições no desenvolvimento tecnológico, consolidando o modo de produção capitalista (OLSSON, 2003, p. 89-90). Sob essa percepção a "iminência da dissolução dos vínculos sociais devido ao apelo extremado ao consumo e aos efeitos devastadores da lógica perversa do capitalismo real de livre mercado" (BEDIN, 1999, p. 124).

Atualmente, o consumo não é tratado apenas como um dos aspectos da sobrevivência física dos seres humanos, como era entendimento antigamente, com o advento da globalização o consumo atinge viés contrários aos seus princípios, posto que é a parte que estrutura e organiza a vida social das pessoas, influenciando outros aspectos da vida moderna. Dessa forma, percebe-se que "o consumo é uma condição e um aspecto permanente e irremovível, sem limites temporais ou históricos; um elemento inseparável da sobrevivência biológica que nós humanos compartilhamos com todos os outros organismos vivos" (BAUMAN, 2008, p. 37).

Por conta dessas transformações, o modo de consumir vem se alterando ao longo dos anos, devido às novidades disponíveis no mercado os consumidores acabam deixando de adquirir produtos para satisfação de suas necessidades pessoais, e são conduzidos pelo marketing e designer de novas ofertas e produtos, que criam hábitos ao consumidor por meio de uma "apoteose" publicitária (BAUMAN, 2008, p. 70). Em decorrência disso "começamos a viver menos na proximidade dos outros homens, na sua presença e no seu discurso; e mais 
sob o olhar mudo de objetos obedientes e alucinantes que nos repetem sempre, o mesmo discurso". (BAUDRILLARD, 2007, p. 15).

Para a concepção de Bauman, o termo consumo não pode ser confundido com a expressão consumismo, posto que "de maneira distinta do consumo, que é basicamente uma característica e uma ocupação dos seres humanos como indivíduos, o consumismo é um atributo da sociedade" (2008, p. 41.).

Percebe-se assim, que o consumo para sobrevivência humana não representa riscos socioambientais, sendo essa etapa um ciclo de nossas necessidades pessoais. Porém, conforme exposto, com a emergência da globalização ao lado da política capitalista provocaram relevantes mudanças no modo de consumir, aflorando a figura consumista na sociedade, para que cada vez mais pessoas consigam adquirir todos os tipos de bens disponíveis no mercado.

Assim, o consumismo está interligado ao excesso do consumo, ou seja, quando o ato de consumir torna-se o verdadeiro propósito da existência de cada pessoa, "nossa capacidade de querer, desejar, ansiar por, e particularmente de experimentar tais emoções repetidas vezes de fato passou a sustentar a economia" (BAUMAN, 2008, p. 38-39).

Diante desse cenário consumista, Bauman classificou o tema como a "sociedade de consumidores" marcada pela forma individualista do ser humano de pensar e de se comportar, isto é "representa o tipo de sociedade que promove, encoraja ou reforça a escolha de um estilo de vida e uma estratégia existencial consumista, e rejeita todas as opções culturais alternativas" (2008, p. 70).

Além da forma individual e irresponsável de consumir, a principal característica da sociedade de consumidores não é apenas a satisfação de vontades por meio de produtos, mas sim "a comodificação ou recomodificação do consumidor: elevar a condição dos consumidores à de mercadorias vendáveis" (BAUMAN, 2008, p. 76).

Para o autor, comodificação presente na sociedade de consumidores quer dizer que "ninguém pode se tornar sujeito sem primeiro virar mercadoria, e ninguém pode manter segura subjetividade sem reanimar, ressuscitar e recarregar de maneira perpétua as capacidades esperadas e exigidas de uma mercadoria vendável” (BAUMAN, 2008, p. 20).

Basicamente a sociedade de consumo significa que o consumismo transforma o consumidor em uma mercadoria. Mas, para Bauman questiona-se: O que significa uma mercadoria? E, como uma pessoa pode se tornar uma mercadoria? 
O primeiro o conceito de mercadoria para o autor não é complicado de ser identificado, porque está diretamente ligada ao mercado, ou seja, é todo produto que pode ser vendido e comercializado, como resultado transformado em dinheiro. Nesse sentido, a mercadoria vai estar relacionada ao sistema capitalista de produção, aonde o consumo irá cada vez mais aquecer grandes empresas a arrecadarem mais dinheiro e aumentarem sua produção.

Por conta dessa característica quando algum ente próximo lhe faz uma roupa de lã para se proteger do frio, esse produto (roupa de lã) para Bauman, não será considerada uma mercadoria, porque não gera dinheiro ao mercado, nem poderá ser trocada ou vendida. Por outro lado, se o mesmo sujeito for diretamente a uma loja e comprar uma roupa de lã, esse produto será considerado uma mercadoria, porque o indivíduo estará contribuindo com o mercado.

Como consequência desse conceito de mercadoria, as pessoas consomem apenas para satisfazer suas futilidades, adquirindo produtos da moda lançada pelo mercado, e, se esquecem de atender suas necessidades pessoais, uma vez que a sociedade de consumo é voltada para "as novas elites do mundo econômico alardeiam sem complexos seus gostos pelos produtos de luxo e pelos símbolos de posição social. [...] O esnobismo, o desejo de parecer rico, o gosto de brilhar, a busca pela distinção social” (LIPOVESTSKY, 2008, p. 51).

O segundo conceito abordado por Bauman, é como a pessoa se torna uma mercadoria? Este ponto crucial da sociedade de consumo está vinculado à própria integridade física, devido à evolução do consumo, estar bem "vestido" perante a sociedade é uma forma de promoção social, fazer uso de carros do ano, comprar os melhores smartphones, possibilita a valorização pessoal. “As pessoas aliciadas, estimuladas ou forçadas a promover uma mercadoria atraente e desejável. Para tanto, fazem o máximo possível e usam os melhores recursos que têm à disposição [...] os produtos são encorajados a colocar no mercado, promover e vender são elas mesmas" (BAUMAN, 2008, p. 13). Nesse sentido, as pessoas começam a desenvolver habilidades, personalidades, gostos e estilos, por meio do consumo “ao explorarem o mercado à procura de bens de consumo, são atraídos para as lojas pela perspectiva de encontrar ferramentas e matérias primas que podem usar para se fazerem aptos a serem consumidos, e, assim valiosos para o mercado" (BAUMAN, 2008, p. 82).

Com base nisso, utilizar mercadorias patrocinadas por grandes marcas desponta a ideia de que "aquele que pode consumir mais e melhores produtos detém o poder social e econômico sobre os outros" (PEREIRA; CALGARO; PEREIRA, 2016, p. 40). 
Sucessivamente, o desejo pelo reconhecimento pessoal para ser "alguém mais" perante a sociedade, revela os principais problemas da sociedade de consumidores, "dividido entre as coisas a serem escolhidas e os que as escolhem; as mercadorias e seus consumidores: as coisas a serem consumidas e os seres humanos que as consomem” (BAUMAM, 2008, p. 20). Dessa forma, o indivíduo torna-se a "sua própria mercadoria desejável” perante a sociedade, posto que sua imagem estará relacionada ao que veste, e não aquilo que produziu em defesa dos benefícios coletivos, "a produção de bens de consumo é agora um fenômeno cultural: compra-se o produto tanto por sua imagem quanto por sua identidade imediata" (JAMESON, 1996, p. 138).

Isto posto, verifica-se que a sociedade de consumidores é marcada pela destreza da importância de consumir para conquistar e elevar seu status pessoal, ocorrendo de maneira individualista e exagerada. Porém, atualmente, a evolução do consumo cresce negativamente em passos largos, de forma que emerge na sociedade contemporânea outro formato de consumo: "O consumocentrismo".

Nesse ápice do consumo, estudado por Cleide Calgaro e Agostinho Oli Koppe Pereira, o sujeito consumocentrista é a sequência dessa dinâmica apresentada pela sociedade de consumo, considerando que a sociedade impõe ao sujeito a disciplina da alimentação, da cultura, da vestimenta, entre outras (CALGARO; PEREIRA 2018, p. 14). Porém, esse novo sistema acrescenta algo a mais o sujeito consumocentrista faz com que o consumo seja o fim em sua existência, ou seja, "seus desejos são pautados no consumo, tornando este o "verdadeiro centro do universo"” (CALGARO; PEREIRA, 2016, p. 57). Assim, as pessoas deixam de ser o centro do universo, perdendo o controle de seus atos para o consumo, uma vez que o sujeito perde o poder de suas decisões perante o mercado, criando outra categoria, na qual "fabrica corpos submissos e exercitados, corpos dóceis" (FOUCAULT, 2011, p.133).

Nesse sentido, o consumocentrismo tem como conceito basilar "o consumo como centro da sociedade. Nesse viés ideológico, só se "é" quando se consegue consumir" (CALGARO, PEREIRA, 2018, p. 17). Percebe-se que a lógica consumocentrista reflete na maneira imprudente que a sociedade de consumidores passou a buscar produtos para encontrar sua felicidade, alcançando um outro patamar, que diretamente perdem controle de sua própria consciência, passando a ser movido pelo mercado.

Portanto, nesse contexto consumocentrista se elege um sistema privilegiado para as classes que tem um maior poder aquisitivo pra consumir o que bem entender, tornando-se os 
legítimos escravos da moda, "tendo consequências imensuráveis para a sociedade e para o meio ambiente, visto que seu modelo econômico, antropofágico e autofágico só se atém ao lucro e a destruição" (CALGARO, PEREIRA, 2018, p. 15).

Assim, estudado a evolução das relações de consumo, passa-se a análise da importância do princípio da solidariedade como meio de retomada ao reconhecimento ao próximo, que será objeto de aprofundamento no próximo tópico.

\section{O PRINCÍPIO DA SOLIDARIEDADE COMO MEIO DE RETOMADA DO RECONHECIMENTO AO PRÓXIMO}

A sociedade de consumo e o consumocentrismo versam o modo irrefletido da população, importando-se apenas com os seus próprios interesses, agindo de modo individual e inconsequente, colocando as pessoas a competirem uma contra as outras, para saber quem tem mais e quem pode mais perante uma comunidade.

As grandes empresas sempre se utilizam de meios para seduzir o consumidor, atualmente com o marketing pela internet, o alcance de lançamentos acaba sendo muito efetivo, a ponto de fazer com que cada cidadão torne-se insatisfeito rapidamente com seu produto atual, buscando comprar o que há de novo no mercado, visando impressionar com seus objetos em ambientes como escolas, universidades, trabalho, lazer, família, entre outros.

Por conta disso, os consumidores acabam sendo notados pela sua própria mercadoria, identificados, assim pela fórmula do "eu sou = o que eu tenho e o que eu consumo", o que acaba afastando o princípio da solidariedade na sociedade consumocentrista (SILVA, REIS, 2018, p. 596).

Nesse sentido, busca-se com o princípio da solidariedade um novo relacionamento entre as pessoas, ser solidário, assim, é partilhar, ao menos, uma mesma época, a solidariedade como valor social que deriva de interesses comuns para cada cidadão, implicando para cada pessoa obrigações morais de reciprocidade ${ }^{1}$ (MORAES, 2006, 240242).

\footnotetext{
${ }^{1}$ Reciprocidade: Cada um, seja o que for que possa querer, deve fazê-lo pondo-se de algum modo no lugar de qualquer outro (MORAES, 2006, p. 242).
} 
A solidariedade deve ser compreendida como um dos complementos dos princípios da liberdade ${ }^{2}$ e igualdade ${ }^{3}$, tendo como base unir pessoas e visar o bem comum. O princípio da solidariedade deve ser interpretado como um fator social sobre a existência humana é uma qualidade ética que serve como reconhecimento de um valor absoluto, resultado de uma consciência moral e de boa-fé, que tem como objetivo evitar lesões aos próximos dentro de uma sociedade (CARDOSO, 2010, p. 91).

O objetivo do princípio da solidariedade representa estar junto dos oprimidos, participando em suas lutas que os afastam culposamente do ciclo social. Isto posto, o princípio da solidariedade não pode ser confundido com caridade ou paternalismo, "[...] A solidariedade é uma forma de amor. Não se pode amar sem ser solidário com o objeto amado" (WARAT, 2004, p. 388). Dessa forma, quando praticada a solidariedade, deve-se reconhecer a existência do outro como diferente, porém, aceitando-o sem pretender alterar o seu modo de ser, pensar ou agir. Verifica-se que este princípio torna-se uma forma fundamental de reclamo, posto que aplicado perante a sociedade possa auxiliar nas responsabilidades mais nobres de nosso compromisso social: auxiliar os excluídos pelo consumo e os existencialmente desaparecidos (WARAT, 2004, p. 388).

Assim, o princípio da solidariedade deve apresentar possibilidades de reconhecimento com o pensamento coletivo de ser bom com e para os outros (LÉVINAS, 2010), uma vez que "quanto mais membros de uma sociedade são solidários ${ }^{4}$, mais mantêm relações diversas seja uns com os outros, seja com o grupo tomado coletivamente, pois, se seus encontros fossem raros, só dependeriam uns dos outros de maneira intermitente fraca" (DURKHEIM, 1999, p. 31-32).

\footnotetext{
${ }^{2}$ Renunciar a liberdade é renunciar à qualidade de homem, aos direitos da humanidade, e até aos próprios deveres [...]. Tal renúncia é incompatível com a natureza do homem, e destituir-se voluntariamente de toda e qualquer liberdade equivale a excluir a moralidade de suas ações (ROUSSEAU, 1978, p. 27).

${ }^{3}$ El concepto de igualdad que forma parte del acervo cultural del pensamiento occidental procede de PLATON y, sobre todo, de ARISTÓTELES: "Parece que la justicia consiste en igualdad, y así es, pero no para todos, sino para los iguales; y la desigualdad parece ser justa, y lo es, en efecto, pero no para todos, sino para los desiguales" (Política 1280a). Essa idea de distribución se presenta con un aura de verdade revelada y debe su éxito a la confrontación con la experiencia histórica a que constituye un enunciado vacío de contenido, para ser más precisos, a que posee un contenido mínimo (la coherencia entre criterio con arreglo al cual se mide la igualdad o la desigualdad y la finalidad de la norma que diferencia) que es además formal (para determinar dicha coherencia, esto es, la razonabilidad de la diferencia, hay que acudir a criterios materiales externos al juicio de igualdad). Cada época histórica ha creído hallar en su particular concepción de igualdad el concepto de la igualdad. El devenir histórico ha dado lugar, a concepciones no sólo diferentes, sino aún contradictorias, que sin embargo, no pueden quebrantar el concepto permanente (MARTíNEZ, 1995, p. 38).

${ }^{4} \mathrm{O}$ vocábulo tem sentido restrito e pragmático. Utiliza-se o termo solidário para designar uma situação em que os sujeitos encontram-se solidários em uma obrigação. "É a ideia de co-responsabilidade perante um dever de uma expectativa de direitos" (MELO, 2007, p. 6)
} 
Em contraponto, os impactos originados pela sociedade consumocentrista criam crises em busca da identidade social, necessita-se consumir para estar integrado ou reconhecido em grupos específicos, e o princípio da solidariedade acaba restando prejudicado por conta desse culto ao consumo. "A solidariedade tornou-se um paradigma perdido" (FARIAS, 1998, p. 194), considerando que as obrigações sociais e voluntárias perderam o espaço para as mercadorias.

Diante da notória ausência de solidariedade nas relações de consumo, os impactos que decorrem por conta do esnobismo pertinente na sociedade consumocentrista acabam promovendo necessidades materiais urgentes, na medida em que o sujeito se sinta desamparado e deprimido devido à tortura espiritual ocasionada pelo consumocentrismo, "por faltar-lhe uma palavra de consolo, de compreensão ou de encorajamento que lhe dê, por exemplo, razão de abandonar uma ideia suicida” (MELO, 2007, p. 6).

Nesse cenário atual, em que emerge a figura do consumismo e do consumocentrismo que aponta o modo individual dos sujeitos pensarem e se comportarem "representa o tipo de sociedade que promove, encoraja, ou reforça a escolha de um estilo de vida e uma estratégia existencial consumista, e rejeita todas as opções culturais alternativas” (BAUMAN, 2008, p. 70).

Por conta disso, originam-se diversos impactos sobre as questões sociais dos seres humanos, posto que "o homem, mais que um indivíduo, é pessoa. A pessoa humana é causa final e eficiente de todo o ordenamento jurídico. Ponto de partida para a compreensão e execução do bem comum” (DI LORENZO, 2010, p. 19).

Assim, para buscar uma retomada ao reconhecimento por meio do princípio da solidariedade necessita-se imprescindivelmente de uma coexistência, "a solidariedade como valor deriva da consciência racional dos interesses em comum, interesses esses que implicam, para cada membro, a obrigação moral de "não fazer aos outros o que não se deseja que lhe seja feito"” (MORAES, 2006, p. 241).

Portanto, para combater a sociedade consumocentrista que transforma as pessoas em mercadorias é importante os princípios da solidariedade como uma virtude e necessidade para que o indivíduo ressurja com os sentimentos "voltados a garantir uma existência digna, comum a todos, numa sociedade que se desenvolve livre e justa, sem excluídos ou marginalizados" (MORAES, 2006. p. 247). 
Para assegurar os conceitos de solidariedade é imprescritível que seja analisado o reconhecimento de responsabilidade ${ }^{5}$ com o próximo, posto que ambos sãos cidadãos e gozam dos mesmos direitos e deveres, não devendo uma pessoa ser excluída por possuir poder econômico para adquirir determinados produtos, porque "da angústia que sofre, sabendo que não há garantia de socorro. Este, se vier, o será por uma iniciativa humanitária e não como garantia de um direito" (MELO, 2007, p. 6).

Com base nisso, quando se trata de solidariedade, deve ser compreendido a pessoa humana como um ser comunitário, "em constante interação com o meio e com os outros seres, pois defende-se a possibilidade de agir em prol de outros membros de grupo coletivo" (SILVA, 2016, p. 115).

Vale destacar a importância do o princípio da solidariedade, que além de ser fundamental para a assegurar a existência digna, constitui um objetivo fundamentais previstos na Constituição República Federal, no art. $3^{\circ}$, inciso I, “construir uma sociedade livre, justa e solidária” (BRASIL, 1988). Não obstante, o Código de Defesa do Consumidor também dispõe, em seu art. $4^{\circ 6}$, o princípio da solidariedade nas relações de consumo: "estabelece em seu inciso III a necessidade de harmonização dos interesses dos participantes nas relações de consumo" (BRASIL, 1990). Assim, o legislador, ao acrescentar o princípio da solidariedade como um princípio inovador no ordenamento jurídico, deve ser analisado não apenas para confirmação de políticas públicas ${ }^{7}$, mas, também, em outras etapas de interpretação e aplicação do direito para alcançar todos os integrantes da sociedade (MORAES, 2016, p. 238239).

\footnotetext{
5 "Os conceitos de responsabilidade e escolha responsável, que antes residiam no campo semântico do dever ético e da preocupação moral pelo Outro, transferiram-se ou foram levados para o reino da autorealização e do cálculo de riscos. Nesse processo, "o Outro" como desencadeador, alvo e critério de uma responsabilidade reconhecida, assumida e concretizada, praticamente desapareceu de vista, afastado ou sobrepujado pelo eu do próprio ator. 'Responsabilidade' agora significa, no todo, responsabilidade em relação a si próprio ('você deve isso a si mesmo', 'você merece', como dizem os corretores do 'alívio da responsabilidade'), enquanto 'escolhas responsáveis' são, no geral, os gestos que atendem aos interesses e satisfazem os desejos do eu” (BAUMAN, 2008, p. 119).

${ }^{6}$ Art. $4^{\circ}$ A Política Nacional das Relações de Consumo tem por objetivo o atendimento das necessidades dos consumidores, o respeito à sua dignidade, saúde e segurança, a proteção de seus interesses econômicos, a melhoria da sua qualidade de vida, bem como a transparência e harmonia das relações de consumo, atendidos os seguintes princípios: [...] III - harmonização dos interesses dos participantes das relações de consumo e compatibilização da proteção do consumidor com a necessidade de desenvolvimento econômico e tecnológico, de modo a viabilizar os princípios nos quais se funda a ordem econômica (art. 170, da Constituição Federal), sempre com base na boa-fé e equilíbrio nas relações entre consumidores e fornecedores.

7 “A expressão política pública designa atuação do Estado, desde a pressuposição de uma bem demarcada separação entre Estado e sociedade[...]. A expressão políticas públicas designa todas as atuações do Estado, cobrindo todas formas de intervenção do poder público na vida social” (GRAU, 2000, p. 21)
} 
Dessa forma, a harmonização do consumo conforme estabelece a legislação, pode ser considerada como um meio de retomada ao reconhecimento do próximo, observando, inclusive, a importância do Estado em proteger o consumidor e os demais excluídos por conta das relações de consumo (SILVA, REIS, 2018, p. 598).

Percebe-se, assim, que o Estado também é responsável, ao lado de todos os membros de uma sociedade, construir uma sociedade solidária por meio de uma justiça social, reconhecendo a todos os cidadãos o acesso aos mesmos direitos.

Por fim, desponta que os ideais do princípio da solidariedade acabam sendo esquecidos por conta das atitudes individuais dos consumidores, podendo gerar riscos não só pessoais mas também ambientais. Portanto, a retomada deste princípio e de seus valores sociais sugere uma saída ao individualismo excessivo que está enraizada e dominada pela sociedade de consumo (REIS, FONTANA, 2001, p. 133).

Assim, os conceitos do princípio da solidariedade como retomada ao reconhecimento do próximo, passa-se a análise do impactos socioambientais originados pela sociedade consumocentrista.

\section{OS IMPACTOS SOCIOAMBIENTAIS OCASIONADOS PELA SOCIEDADE DE CONSUMOCENTRISTA}

O socioambientalismo tem como marco histórico a Conferência das Nações Unidas sobre Meio Ambiente e Desenvolvimento, realizada no Rio de Janeiro, no ano de 1992, conhecida como Eco-92. Tem como objetivo acrescentar inovações ligadas à política, questões sociais e meio ambiente em todo o mundo.

Nas palavras de Santilli (2005, p. 34) movimentos socioambientais desenvolvem-se com base na concepção que:

[...] em um país pobre e com tantas desigualdades sociais, um novo paradigma de desenvolvimento deve promover não só a sustentabilidade estritamente ambiental - ou seja, a sustentabilidade em espécies, ecossistemas e processos ecológicos - como também a sustentabilidade social - ou seja, deve contribuir também com a redução da pobreza e das desigualdades sociais e promover valores como justiça social e equidade. Além disso, o novo paradigma de desenvolvimento preconizado pelo socioambientalismo deve promover e valorizar a diversidade cultural e a consolidação do processo democrático no país, com ampla participação social na gestão ambiental. 
Dessa conforma, com base nesse conceito, percebe-se que socioambientalismo está relacionado à proteção e a promoção do desenvolvimento de uma sustentabilidade ambiental como social, objetivando a defesa do meio ambiente e das desigualdades sociais, "uma vez que os problemas ambientais são, antes de tudo, problemas sociais, problemas do ser humano" (BECK, 2010, p. 98).

No tópico anterior, de acordo com o princípio da solidariedade foi apontado os prejuízos que destoam devido a sociedade consumocentrista, principalmente pela ausência do reconhecimento ao próximo e a separação de classes ocasionadas pelo consumo excessivo. Nesse sentido, percebe-se que esse problema também pode ser considerado um impacto socioambiental, por tratar de danos diretamente ligados à sociedade, posto que o consumismo cria raízes entre as pessoas, tornando-se, muitas vezes, uma válvula de escape, “o último reduto da autoestima em uma sociedade que está perdendo rapidamente a noção da família, de convivência social, e em cujo seio da violência, o isolamento e o desespero dão sinais alarmantes de crescimento" (PENNA, 1999, p. 216). Portanto, o consumocentrismo deve ser regido por regras e valores morais, com base no princípio da solidariedade, de acordo com decisões em que "o que comprar, quanto gastar e quanto economizar, são, portanto, decisões morais que expressam e produzem cultura" (PORTILHO, 2005, p. 203).

Não obstante, as consequências não se esgotam apenas em problemas sociais, posto que "enquanto as necessidades do ser humano, sobretudo quanto alimentado pelo marketing, são infinitas, os recursos naturais são finitos, sobretudo quando não renováveis" (FILOMENO. 2007, p. 20). Nesse cenário, desponta que a sociedade consumocentrista aumenta a produção das grandes empresas, e, consequentemente, cresce a necessidade de obter maiores recursos naturais para continuar a produzir mercadorias para atingir esse público. Nesse sentido, a preservação ambiental não pode ser esquecida, porque gera a "necessidade de oferecer à população futura as mesmas condições e recursos naturais de que dispõe a geração presente" (OLIVEIRA, 2006, p. 21). Acrescenta Latouche que "o crescimento, hoje, só é um negócio rentável se seu peso cair sobre a natureza, as gerações futuras, a saúde dos consumidores, as condições de trabalho dos assalariados e, mais ainda, sobre os países do Sul" (LATOUCHE, 2009, p. 39).

O problema dessa maneira de viver e de se comportar que emerge na sociedade consumocentrista é "o fetichismo pelo novo em detrimento do que é velho, referindo-se que a 
sociedade de consumo está atrelada não só a produção, mas também ao descarte, levando os objetos o mais rapidamente possível para o lixo" (BAUMAN, 2007, p. 31-32). Para tirar proveito dessa situação, as grandes empresas direcionam a produção em larga escala de produtos, sem se preocupar com aa validade de cada mercadoria, mas, sim, com a intenção de diminuir a duração dos objetos para que cada vez tenham um menor tempo útil de vida, programando uma "função de morte" com o intuito de deixar o mercado sempre aquecido (BAUDRILLARD, 2003, p. 65).

Acerca dessa perspectiva, além da difícil reciclagem que muitos produtos possuem, em especial os eletrônicos ${ }^{8}$ que apresentam componentes tóxicos contaminando a fauna e a flora do planeta. A capacidade de regeneração da Terra não consegue acompanhar a produção em massa das grandes empresas, posto que o homem transforma os produtos em lixos eletrônicos (e-lixos $\left.{ }^{9}\right)$ mais rápido que a recomposição da natureza (LATOUCHE, 2009). A acumulação de lixo deposita significativos impactos sicioambientais a cada ano, devido à aglomeração das sobras dos e-lixos que danificam o meio ambiente e todas as espécies de vida existentes (MAGERA, 2012).

Além disso, o mercado automobilístico movimenta cerca de 1,3 bilhões de veículos no mundo, e de acordo com pesquisas realizadas pela Organização das Nações Unidas ONU, no ano de 2050, esses números podem ultrapassar marcas de 2 bilhões de carros, ocasionando consequências severas para o meio ambienta e a saúde dos habitantes (ONU, 2015).

O efeito desse ciclo vicioso provoca extensos impactos socioambientais para a sociedade, porque a intensa compra de mercadorias combinado com a aceleração da produção de novos produtos, do mercado encontram-se consolidados subliminarmente em nosso estilo de vida, na oportunidade que as roupas de grife, estilos musicais, e até as religiões são consumidos, destruídos e descartados em um ritmo cada vez maior (LIPOVESTSKY, 2007, p. $67)$.

\footnotetext{
8 "O lixo eletrônico, ou e-lixo, um pesadelo global. A cada ano, entre 5 a 7 milhões de toneladas de eletrônicos tornam-se obsoletos. Seus componentes tóxicos contaminam a terra, o ar, água e o todos os habitantes do planeta" (LEONARD, 2011, p. 69).

9 . Os "e-lixos" como são conhecidos, oferecem perigo à saúde humana devido a sua composição baseada em cobre, ouro, chumbo, níquel, zinco, berílio, tântalo, arsênico, mercúrio e outros. E, "todos esses materiais são usados na produção, e depois, quando o produto fica obsoleto, tudo vai parar nos lixões. Tudo o que compôs esses objetivos e contribuiu para uma criação industrial, vai permanecer no ar, na terra e na água durante anos, até séculos!" (MAGERA, 2012, p. 107).
} 
Sob essa ótica, os efeitos da sociedade consumocentrista produzem uma insegurança para todas as pessoas, posto que contribuem de forma negativa para a decomposição do meio ambiente, além de, causar vícios de consumo insanáveis para muitas pessoas, podendo provocar graves doenças, porque que os novos riscos "não estão vinculados ao lugar em que foram gerados - a fábrica. De acordo com seu feitio, eles ameaçam a vida do planeta, sob todas as suas formas" (BECK, 2011, p. 43).

Para enfrentar esses problemas ambientais necessariamente a sociedade consumocentrista precisa passar por uma "correção do quadro alarmante de desigualdade social da falta de acesso da população pobre aos seus direitos sociais básicos, o que, diga-se de passagem, também é causa pontencializadora da degradação ambiental" (FENSTERSEIFER, 2008, p. 93-94).

Neste caso, resta evidente que o consumismo degrada não só o meio ambiente, mas também nossa sociedade, que carece de informações sobre o modo de consumir e de reciclar, uma vez que "sociedade e natureza são reabsorvidas uma na outra e uma pela outra porque ambas deixaram de ser um princípio interno de estruturação e diferenciação das ações naturais e humanas para se tornarem, abstratamente meio ambiente" (CHAUÍ, 2003, p. 07).

Além disso, diante de todos os impactos socioambientais que ocorrem no cotidiano, não pode deixar de ser observado o princípio da proibição do retrocesso, princípio constitucional implícito, com o dever de progressividade em matéria tanto de direitos sociais, econômicos, culturais e ambientais (SARLET, FENSTERSEIFER. 2011, p. 18-19).

Dessa forma, as políticas ambientais e sociais devem buscar o equilíbrio para compatibilizar as necessidades entre: "a industrialização e o desenvolvimento, com as de proteção, restauração e melhora do ambiente. Trata-se, na verdade, de optar por um desenvolvimento econômico qualitativo, único, capaz de propiciar uma real elevação da qualidade de vida e bem-estar social” (PRADO, 1992, p. 675). Para manter a biodiversidade, "é essencial poupar uma parte da capacidade produtiva da biosfera para garantir a sobrevivência das outras espécies, particularmente as espécies selvagens" (LATOUCHE, 2009, p. 30).

De qualquer forma, o meio ambiente sempre foi um empecilho para o crescimento econômico das grandes empresas, e mesmo assim não é suficientemente capaz de reduzir o poder das corporações transnacionais, que devido ao seu elevador capital conseguem atingir seus objetivos finais: o lucro sem se preocupar com qualquer consequência, visto que essas 
empresas "são capazes, também, de mobilizar significativos recursos para financiar campanhas políticas, pesquisas científico-tecnológicas e a própria vida econômica das comunidades onde pretendam instalar-se" (CRETELLA NETO, 2006, p. 58). Hawken, acrescenta que "nossas mentes estão sendo dirigidas pela mídia corrompedora a serviço dos mentores das corporações, cujo propósito é reorganizar a realidade de maneira que os observadores esqueçam o mundo em volta deles" (1993, p. 132).

Atualmente vivemos em constantes conflitos que transmite reflexões sobre o socioambientalismo, diante de todos os impactos que a sociedade consumocentrista geram a sociedade, demonstrando que as relações de consumo influenciam no reconhecimento ao próximo, distanciando pessoas e separando classes sociais, bem como aos danos ambientais que por conta da produção em alta escala das grandes empresas (para atender os consumidores) estão arruinando com o ecossistema denegrindo a recomposição do planeta terra. Por fim, necessita-se cada vez mais da consciência de cada cidadão observando os vieses contidos nos princípios da solidariedade, para garantir uma existência digna e comum a todos.

\section{CONSIDERAÇÕES FINAIS}

O tema atual do trabalho possui grande relevância diante dos problemas socioambientais que se enfrentam atualmente. A aquisição exagerada de produtos e serviços de forma irresponsável acarreta sérios danos, muitas vezes irreparáveis ao meio ambiente, que podem colocar em risco a existência humana, visto que as próprias pessoas tornam-se mercadorias para cultuar o consumocentrismo.

Nesse passo, ao analisar o princípio da solidariedade, nota-se a importância de reconhecer o próximo excluído, para que não agrave a situação atual, onde grupos sociais, familiares, não se dividam por conta de um consumo inconsciente e individualista.

Foi comprovado no presente artigo, que o consumocentrismo degrada não somente o meio ambiente, mas também nossa sociedade como um todo, que carece de informações sobre o modo de consumir e de reciclar. Por conta disso, foi possível que o consumocentrismo separa classes e ao mesmo tempo gera prejuízos praticamente irrecuperáveis ao meio ambiente, ao passo que o meio ambiente não consegue se regenerar na mesma proporção em que as grandes empresas exploram as riquezas naturais da fauna e flora. 
Constatou-se também, que a progressão do quadro alarmante de desigualdade social da falta de acesso da população mais carente aos seus direitos sociais básicos, potencializará uma degradação ambiental imensurável, como inclusive já aconteceu no Brasil, em desastres ambientais ocorridos pela ausência do princípio da solidariedade.

Nesse sentido, o presente artigo como possível saída para enfrentar os problemas socioambientais a importância da consciência de cada cidadão para que os vieses do princípio da solidariedade sejam retomados e alcancem todas as pessoas, inclusive as mais pobres, para assegurar a existência das próximas gerações e o garantir o reconhecimento a todas as classes, independente do poder econômico particular de cada sujeito.

Por fim, não se pode negar que o Estado, como responsável primário pelas garantias socioambientais, encontra-se limitado perante o poder econômico das corporações transnacionais que utilizam-se do meio ambiente para gerar cada vez mais lucro, aumentar seu capital, e aprimorar novos produtos para a sociedade consumocentrista.

\section{REFERÊCIAS}

BAUDRILLARD, Jean. A sociedade de consumo. Lisboa: Edições 70, 2007.

BAUMAN, Zygmunt. Vida para consumo: a transformação das pessoas em mercadorias. Rio de Janeiro: Editora Zahar, 2008.

BEDIN, Gilmar Antonio. Estado, cidadania e globalização do mundo: algumas reflexões e possíveis desdobramentos. In: OLIVEIRA, Odete Maria de (Coord.). Relações internacionais e globalização: grandes desafios. 2 ed. Ijuí: Unijuí, 1999. p. 123-150.

BECK, Ulrich. Sociedade de risco: rumo a uma outra modernidade. Trad. Sebastião Nascimento, São Paulo, 2010.

BRASIL. Constituição da República Federativa do Brasil de 1988. Disponível em: http://www.planalto.gov.br/ccivil_03/constituicao/constituicao.htm. Acesso em: 28 set. 2019.

BRASIL. Lei no 8.078, de 11 de setembro de 1990. Disponível em: http://www.planalto.gov.br/ccivil_03/leis/18078.htm. Acesso em: 28 set. 2019.

CARDOSO, Alenilton da Silva. Princípio da solidariedade: o paradigma ético do direito contemporâneo. São Paulo: Editora Juarez de Olveira, 2010.

CALGARO, Cleide; PEREIRA, Agostinho Oli Koppe. A sociedade consumocentrista e a disciplina do sujeito na modernidade: uma análise dos impactos socioambientais. In: Carolina Medeiros Bahia, Cleide Calgaro (Orgs.). Direito, globalização e responsabilidade nas relações de consumo I [Recurso eletrônico on-line] organização CONPEDI/UNICURITIBA, 2016. 
CALGARO, Cleide; PEREIRA, Agostinho Oli Koppe. O constitucionalismo latinoamericano e a sociedade consumocentrista: por uma democracia socioecológica. In: Cleide Calgaro (Org.) Direito socioambiental [recurso eletrônico], Caxias do Sul, RS: Educs, 2018.

CHAUÍ, Marilena. A universidade pública sob nova perspectiva. Revista Brasileira de Educação, n. 24, 2003.

CRETELLA NETO, José. Empresa transnacional e direito internacional: exame do tema à luz da globalização. Rio de Janeiro: Forense, 2006.

DI LORENZO, Wambert Gomes. Teoria do estado de solidariedade: da dignidade da pessoa humana aos seus princípios corolários. Rio de Janeiro: Elsevier, 2010.

DURKHEIM, Émile. Da divisão do trabalho social. São Paulo: Martins Fontes, 1999.

FARIAS, José Fernando de Casto. A origem do direito de solidariedade. Rio de Janeiro: Renovar, 1998, p. 194.

FENSTERSEIFER, Tiago. Direitos fundamentais e proteção do ambiente: a dimensão ecológica da dignidade humana no marco jurídico constitucional do estado socioambiental de direito. Porto Alegre: Livraria do Advogado Editora, 2008.

FILOMENO, José Geraldo Brito. Curso fundamental de direito do consumidor. São Paulo: Atlas, 2007.

FOUCAULT, Michel. Vigiar e punir: nascimento da prisão. 38. ed. Trad. Raquel Ramalhete. Petrópolis, RJ: Vozes, 2011.

GRAU, Eros Roberto. O direito posto e o direito pressuposto. São Paulo: Malheiros, 2000.

HAWKEN, Paul. The ecology of commerce: a declaration of sustainability. Nova York. Happy Business, 1993.

JAMESON, Frederic. Pós-modernismo: a lógica cultural do capitalismo tardio. São Paulo: Ática, 1996.

MAGERA, Márcia. Os caminhos do lixo: a obsolescência programada à logística reservada. Campinas: Editora Átomo, 2012.

LATOUCHE, Serge. Pequeno tratado do decrescimento severo. São Paulo: Editora WMF Martins Fontes, 2009.

LEONARD, Annie. A história das coisas: da natureza ao lixo, o que acontece com tudo que consumimos. Rio de Janeiro: Editora Zahar, 2011

LÉVINAS, Emmanuel. Entre nós: ensaios sobre a alteridade. Trad. Pergentino Stafano Pivatto. Petrópolis/RJ: Vozes, 2010.

LIPOVETSKY, Gilles. O luxo eterno: da idade do sagrado ao tempo das marcas. São Paulo: Companhia das Letras, 2008. 
LIPOVETSKY, Gilles. A felicidade paradoxal: ensaios sobre a sociedade de hiperconsumo. Trad. Maria Lúcia Machado. São Paulo: Companhia das Letras, 2007.

MARTÍNEZ, Fernando. El derecho fundamental a no ser discriminado por razón de sexo. Madrid, McGraw-Hill, 1995.

MELO, Osvaldo Ferreira de. Sobre direitos e deveres de solidariedade. Revista Jurídica CCJ/FURB. v. 11. n. 22, p. 3-14, jul./dez. 2007.

MORAES, Maria Celina Bodin de. Na medida da pessoa humana: estudos de direito civilconstitucional. Rio de Janeiro: Processo, 2016, p. 238-239.

MORAES, Maria Celina Bodin de. O princípio de solidariedade. In: PEIXINHO, Manoel Messias; GUERRA, Isabella Franco; NASCIMENTO FILHO, Firly. Os princípios da Constituição de 1988. 2 ed. Rio de Janeiro: Lumes Juris, 2006.

OLIVEIRA, Gilson Baptista de; SOUZA LIMA, José Edmilson de. O desenvolvimento sustentável em foco: uma contribuição multidisciplinar. São Paulo: Annabilume, 2006.

OLSSON, Giovanni. Relações internacionais e seus atores na era da globalização. Curitiba: Juruá, 2003.

ORGANIZAÇÃO DAS NAÇÕES UNIDAS. ONU: Com mais de 1 bilhão de veículos, planeta precisa de modelo mais sustentável de transporte. 2015. Disponível em: https://nacoesunidas.org/com-mais-de-1-bilhao-de-veiculos-planeta-precisa-de-modelo-maissustentavel-de-transporte-afirma-onu Acesso em: 27 ago. 2018

PENNA, Carlos Gabaglia. O Estado do planeta: sociedade de consumo e degradação ambiental. Rio de Janeiro: Record, 1999.

PEREIRA, Agostinho Oli Koppe; CALGARO, Cleide; PEREIRA. Desenvolvimento sustentável e o consumocentrismo: o paradoxo da modernidade. In: PEREIRA, Agostinho O. Koppe; CALGARO, Cleide; PEREIRA, Henrique M. Koppe (Orgs).. O consumo da sociedade moderna [recurso eletrônico]: consequências jurídicas e ambientais. Caxias do Sul, RS: Edusc, 2016.

PORTILHO, Fátima. Consumo verde, consumo sustentável e ambientalização de consumidores. São Paulo: Cortez, 2005.

PRADO, Luiz Regis. A tutela constitucional do ambiente no Brasil. Revista dos Tribunais, São Paulo, ano 81, v. 675, jan. 1992.

REIS, Jorge Renato dos; FONTANA, Eliane. A hermenêutica filosófica e o princípio da solidariedade como sustentáculos dos direitos fundamentais. In: MOZETIC, Vinícius Almada; RESINA, Judith Solé. Reflexões e Dimensões do Direito: uma cooperação internacional entre Brasil e Espanha. Curitiba: Multideia, 2011.

SANTILLI, Juliana. Socioambientalismo e novos direitos: proteção jurídica à diversidade biológica e cultural. São Paulo: Peirópolis, 2005.

SARLET, Ingo Wolfgang; FENSTERSEIFER, Tiago. Notas sobre os deveres de proteção do Estado e a garantia da proibição de retrocesso em matéria socioambiental. In: STEINMETZ, 
Wilson; AUGUSTIN, Sérgio (Org.). Direito constitucional do ambiente. Caxias do Sul: Educs, 2011.

SILVA, Rogerio da. A concretização do direito fundamental de proteção ao consumidor/cidadão vulnerável: um debate acerca das intersecções público-privado em face da proposta de políticas públicas de autonomia dos PROCONS. Tese (Doutorado em Direito) - Universidade de Santa Cruz do Sul - UNISC. Santa Cruz do Sul, 2016.

SILVA, Rogerio da; REIS, Jorge Renato dos. O desafio da aplicação do princípio da solidariedade na sociedade hiperconsumista que cultua o descartável. Revista Justiça do Direito. UPF. v. 32, n. 3, p. 583-607, set./dez. 2018.

ROUSSEAU, Jean-Jacques. Discurso sobre a origem e os fundamentos das desigualdades entre os homens. Coleção Os Pensadores. São Paulo: $2^{\circ}$ edição, Abril Cultura, 1978.

WARAT, Luiz Alberto. Surfando na pororoca: o oficio do mediador. Florianópolis: Fundação Boieteux, 2004, v.3, p.388. 